\title{
A Survey of Push and Pull Motivations of Green Event Tourists
}

\author{
Yu-Fen Chen and Huai-En Mo
}

\begin{abstract}
This study offers an attempt to understand green event tourist motivation. The study suggests that the conceptual framework of push, pull, and constraint factors in the literature was generally supported. The study reconfirms that green event tourists' behavior is driven by internal and external factors. In other words, they decide to go on a green event because they want to fulfill their intrinsic desire, and at the same time, their decisions on where to go are based on destination attributes and constraints.
\end{abstract}

Index Terms-Green event tourism, tourist motivation push and pull motive.

\section{INTRODUCTION}

In the past decades, the sustainable development of tourism was received increased attention by both tourism practitioners and travelers [1]. As the environmental movement got underway and the environmental awareness came into focus in the late twentieth century, the tourism industry began incorporating environmentally responsible or "green" innovations into their businesses. The travelers also have become increasingly aware of the need for environmental protection [2]. To help improve relations with local communities, reduce costs, and attract green conscious attendees, green events across the country are making efforts to reduce tourists' footprint. According to a recent study conducted in 2012 by the Center for Sustainable Tourism and the Business School at East Carolina University, $57.6 \%$ of festival attendees think it is either very important or important for festival and events to implement green practices. The same study found that $66.5 \%$ are more likely to attend a festival or event that had implemented green practices, and $29.3 \%$ attendees would be willing to pay more to attend an event that had implemented green practices (abstract from www.agreenerfestival.com at Nov. 15, 2012) [3].

Given the complexity of the motivation construct, it is not surprising that push and pull factors have been researched either as separate [4], [5] or related constructs [6]-[9]. The closer we move to appreciate what cause individuals to value an organization's green efforts, the better marketers will be able to develop strategies specifically targeted at these tourists. To date there has little information has been documented about motivations on green event tourists in Taiwan. In recognizing the fact that knowing the importance of both push and pull factors can help the destination meet the desired needs of individual tourists from different

Manuscript received September 16, 2013; revised November 21, 2013.

Yu-Fen Chen is with the Chihlee Institute of Technology, Taiwan (R.O.C) (e-mail: bephd@ mail.chihlee.edu.tw). markets, this study has carefully selected Taipei County Sustainable Development Education Center, located at Bali Zou-an Park, as the primary case study site. Bali Zou-an Park is a famous scenic spot in New Taipei City, with the number of visitor arrivals more than 2.6 millions in 2012 [10]. Thus, this paper attempts to identify motivation factors of green event tourists to Taipei County Sustainable Development Education Center as they demonstrate different domains of behavior, which may have important marketing implications to the country. At the same time, knowledge of tourist's motivation is critical to predict future travel patterns.

\section{LITERATURE REVIEW}

The term event is used for describing different activities designed for different purposes. These activities can be art, sports, tourism and social activities, and can also be activities organized by giant organizers more professional and more formal [11]. The event is all about people-people coming together to create, operate, and participate in an experience [12]. It is an activity that gathers the target group in time and room, a meeting where a message is communicated and happening is created [13]. According to Berridge [14], events are a unique moment in time and aside from everyday occurrences. Public or private, commercial or charitable, celebratory or commemorative-events bring people together to share an experience and produce a measurable outcome [12]. Civic events, conventions, expositions, fairs and festivals, hallmark events, hospitality, incentive travel, meetings and conferences, retail events, reunions, social life-cycle events, sport events, and tourism are the examples of subfields of events [15]. Events not only bring people together but also can provide significant economic benefits [16]. The event industry is one of the world's largest employers and contributes major positive economic impact [17].

In recent years, more attention has been given to behavior and choices in relation to festivals and special events. The study of Mohammad and Som [5] reconfirmed that tourists' travel behavior is driven by internal and external factors. In other words, tourists decide to go on a holiday because they want to fulfill their intrinsic desires, and at the same time, their decisions on where to go are based on destination attributes. Park and Yoon [18] conducted a survey to segment and profile the motivations of tourists. The results showed that six dimensions of motivation among the rural tourists included relaxation, socialization, learning, family togetherness, novelty, and excitement. They also suggest that the market can be divided into four segments based on tourists' motivation: family togetherness, passive tourists, want-it-all, and learning and excitement. Prayag and Ryan 
[9] used qualitative research techniques to understand the relationship between the push and pull factors of a tourist destination and the influence of nationality on these factors. The results indicated that different motives for visiting Mauritius were found to exist between national groupings.

Overall, the contribution of the previous festival and event motivation studies were descriptive in nature, and contributed in two aspects: 1) a research framework for surveying festival and event motivation was developed, and 2) the relationships between motivation and other variables were investigated. In this study, the author developed a list of motivation items and asked respondents to indicate the importance of each item in their green event attending motivations, and finally the results were then factor analyzed into several dimensions.

\section{METHODOLOGY}

\section{A. Survey Instrument}

To explore the above mentioned variables, the questionnaire-based interview was considered the most suitable method. The design of the questionnaire has been based on the study on event visitation motivation [19], and the literature review combined with the own ideas of the author of this study. The questionnaire includes 6 questions and 29 statements divided into 4 sections.

\section{B. Sampling}

The interviews were basically conducted at one particular spot in Taipei County Sustainable Development Education Center, located at Bali Zou-an Park which is a famous scenic spot in New Taipei City, at every Saturday and Sunday during April to May 2013. The number of visitor arrivals at Bali Zou-an Park was more than 2.6 millions in 2012 (Tourism Bureau, MOTC, 2013). Numerous tourists usually sit around the building to eat and drink something. It was found that this area was most suitable to accomplish the interview because most people were having food or talking so they had most likely interest and time to participate.

Approximately 300 tourists were asked to participate and 198 persons reacted positive on that (response rate was $66 \%$ ). Reasons for non-participation were a lack of time or no interest. The questions were asked in order as outlined in the questionnaire.

\section{RESEARCH FINDINGS}

The author started to set out the research objectives of this study. The four main questions of this research are divided into background, push factors, pull factors and constraints. In order to demonstrate the relationship among these research areas the author created a model, based on a combination of literature, which shows the link between the factors on influence.

\section{A. Mean Values of Push Motives and Pull Motives}

Table I and Table II respectively, rank the mean values of push motive, pull motive, and constraint items from the highest to the lowest. In Table I, seven items recorded mean values above 4 while eight items were placed between the ranges of 3.16 to 3.93. The item "By attending a green event I visit a place that I have not visited before." recorded the highest mean value of 4.35 , while item "By attending a green event I could meet people with similar interests. " recorded the lowest mean value (2.60). In Table II, the item "The beauty of the event location makes me want to visit a green event." obtained the highest mean value of 4.19 followed by item "I would like to learn something about the destination where the green event is held. (4.14)". The item "The green event is the only reason I travelled towards the destination." were placed at the lower score (2.67).

TABLE I: MeAn VALUeS of Push Motive Items

\begin{tabular}{|c|c|c|}
\hline Push Items & Ranking & Mean \\
\hline $\begin{array}{l}\text { 1. By attending a green event I visit a place } \\
\text { that I have not visited before. }\end{array}$ & 1 & 4.35 \\
\hline $\begin{array}{l}\text { 3. Visiting a green event is for me a form of } \\
\text { relaxation. }\end{array}$ & 1 & 4.32 \\
\hline $\begin{array}{l}\text { 9. Attending a green event gives me an } \\
\text { opportunity to meet new people. }\end{array}$ & 1 & 4.24 \\
\hline $\begin{array}{l}\text { 8. I enjoy participating in the activity of the } \\
\text { event while attending a green event. }\end{array}$ & 1 & 4.18 \\
\hline $\begin{array}{l}\text { 14. By attending a green event I could } \\
\text { increase my social status. }\end{array}$ & 1 & 4.16 \\
\hline $\begin{array}{l}\text { 15. Attending a green event would impress } \\
\text { my friends and family. }\end{array}$ & 1 & 4.14 \\
\hline $\begin{array}{l}\text { 7. The atmosphere at a green event makes me } \\
\text { want to visit. }\end{array}$ & 1 & 4.09 \\
\hline $\begin{array}{l}\text { 2. By attending a green event I get away } \\
\text { from daily life stress. }\end{array}$ & 2 & 3.93 \\
\hline $\begin{array}{l}\text { 4. Attending a green event makes me feel } \\
\text { relaxed. }\end{array}$ & 2 & 3.86 \\
\hline $\begin{array}{l}\text { 12. I would like to experience a green event } \\
\text { visit as being an earthman. }\end{array}$ & 2 & 3.86 \\
\hline $\begin{array}{l}\text { 11. Attending a green event gives me an } \\
\text { opportunity to enjoy a day out. }\end{array}$ & 2 & 3.84 \\
\hline $\begin{array}{l}\text { 13. Attending a green event make me } \\
\text { reconnect spirtual roots. }\end{array}$ & 2 & 3.83 \\
\hline $\begin{array}{l}\text { 5. Attending a green event is for me a form } \\
\text { of self-exploration. }\end{array}$ & 2 & 3.58 \\
\hline $\begin{array}{l}\text { 6. Attending a green event makes me satisfy } \\
\text { the desire to be somewhere else. }\end{array}$ & 3 & 3.30 \\
\hline $\begin{array}{l}\text { 10. Attending a green event is for me a form } \\
\text { of socialization. }\end{array}$ & 3 & 3.16 \\
\hline $\begin{array}{l}\text { 16. By attending a green event I could meet } \\
\text { people with similar interests. }\end{array}$ & 4 & 2.60 \\
\hline
\end{tabular}

Note: If the value of mean is $>$ (or $=$ ) 4 , the ranking is 1 . If the value of mean is $>$ (or $=$ ) 3.5 and $<4$, the ranking is 2 . If the value of mean is $>$ (or $=$ ) 3 and $<3.5$, the ranking is 3 . If the value of mean is $<3$, the ranking is 4 .

TABLE II: Mean VALues of Pull Motive Items

\begin{tabular}{lll}
\hline Pull Items & Ranking & Mean \\
\hline $\begin{array}{l}\text { 4. The beauty of the event location makes me } \\
\text { want to visit a green event. }\end{array}$ & 1 & 4.19 \\
$\begin{array}{l}\text { 5. I would like to learn something about the } \\
\text { destination where the green event is held. }\end{array}$ & 1 & 4.14 \\
$\begin{array}{l}\text { 6. I would like to learn more knowledge } \\
\text { about the green event. }\end{array}$ & 2 & 3.95 \\
$\begin{array}{l}\text { 2. Attending a green event makes me realize } \\
\text { to be an environmentalist. }\end{array}$ & 2 & 3.89 \\
$\begin{array}{l}\text { 8. I would like to experience the culture of } \\
\text { the place/park where the green event is held. }\end{array}$ & 2 & 3.88 \\
$\begin{array}{l}\text { 10. The easy transportation makes me want } \\
\text { to visit a green event. }\end{array}$ & 2 & 3.73 \\
$\begin{array}{l}\text { 9. The inexpensive price level makes me } \\
\text { want to visit a green event. }\end{array}$ & 2 & 3.65 \\
$\begin{array}{l}\text { 1. Attending a green event has always been a } \\
\text { dream for me. }\end{array}$ & 3 & 3.26 \\
$\begin{array}{l}\text { 3. To see some famous persons (actors or } \\
\text { artists) makes me want to visit a green event. }\end{array}$ & 3 & 3.07 \\
$\begin{array}{l}\text { 7. The green event is the only reason I } \\
\text { travelled towards the destination. }\end{array}$ & 4 & 2.67 \\
\hline
\end{tabular}

Note: If the value of mean is $>$ (or $=$ ) 4 , the ranking is 1 . If the value of mean is $>$ (or $=$ ) 3.5 and $<4$, the ranking is 2 . If the value of mean is $>$ (or $=)$ 3 and $<3.5$, the ranking is 3 . If the value of mean is $<3$, the ranking is 4 . 


\section{B. Factor Analysis of Push Motives and Pull Motives}

TABLE III: FACTOR ANALYSIS OF PUSH MOTIVE ITEMS

\begin{tabular}{|c|c|c|c|c|c|c|}
\hline Push Factors & Factor loading & Communality & Eigen Value & Variance & Me-an & S.D. \\
\hline Socialization & & & 1.90 & 11.19 & 2.68 & 0.73 \\
\hline $\begin{array}{l}\text { 16. By attending a green event I could meet people with } \\
\text { similar interests. }\end{array}$ & 0.74 & 0.58 & & & & \\
\hline $\begin{array}{l}\text { 17. To attend a green event I can talk about when I get } \\
\text { home. }\end{array}$ & 0.68 & 0.57 & & & & \\
\hline $\begin{array}{l}\text { 10. Attending a green event is for me a form of } \\
\text { socialization. }\end{array}$ & 0.64 & 0.46 & & & & \\
\hline Prestige & & & 1.66 & 9.76 & 4.15 & 0.68 \\
\hline $\begin{array}{l}\text { 15. Attending a green event would impress my friends } \\
\text { and family. }\end{array}$ & 0.77 & 0.71 & & & & \\
\hline $\begin{array}{l}\text { 14. By attending a green event I could increase my social } \\
\text { status. }\end{array}$ & 0.70 & 0.55 & & & & \\
\hline Entertainment & & & 1.50 & 8.84 & 4.11 & 0.50 \\
\hline $\begin{array}{l}\text { 2. By attending a green event I get away from daily life } \\
\text { stress. }\end{array}$ & 0.70 & 0.53 & & & & \\
\hline $\begin{array}{l}\text { 8. I enjoy participating in the activity of the event while } \\
\text { attending a green event. }\end{array}$ & 0.62 & 0.48 & & & & \\
\hline $\begin{array}{l}\text { 7. The atmosphere at a green event makes me want to } \\
\text { visit. }\end{array}$ & 0.48 & 0.41 & & & & \\
\hline $\begin{array}{l}\text { 9. Attending a green event gives me an opportunity to } \\
\text { meet new people. }\end{array}$ & 0.39 & 0.47 & & & & \\
\hline Self-exploration & & & 1.32 & 7.76 & 3.76 & 0.60 \\
\hline $\begin{array}{l}\text { 12. I would like to experience a green event visit as being } \\
\text { an earthman. }\end{array}$ & 0.69 & 0.51 & & & & \\
\hline $\begin{array}{l}\text { 5. Attending a green event is for me a form of } \\
\text { self-exploration. }\end{array}$ & 0.55 & 0.39 & & & & \\
\hline $\begin{array}{l}\text { 13. Attending a green event make me reconnect spiritual } \\
\text { roots. }\end{array}$ & 0.49 & 0.51 & & & & \\
\hline Relaxation & & & 1.13 & 6.64 & 4.09 & 0.58 \\
\hline 3. Visiting a green event is for me a form of relaxation. & -0.66 & 0.55 & & & & \\
\hline 4. Attending a green event makes me feel relaxed. & 0.62 & 0.52 & & & & \\
\hline Escapism & & & 1.05 & 6.20 & 3.83 & 0.55 \\
\hline $\begin{array}{l}\text { 1. By attending a green event I visit a place that I have } \\
\text { not visited before. }\end{array}$ & 0.67 & 0.55 & & & & \\
\hline $\begin{array}{l}\text { 11. Attending a green event gives me an opportunity to } \\
\text { enjoy a day out. }\end{array}$ & 0.56 & 0.42 & & & & \\
\hline $\begin{array}{l}\text { 6. Attending a green event makes me satisfy the desire to } \\
\text { be somewhere else. }\end{array}$ & -0.41 & 0.35 & & & & \\
\hline Total Variance explained & & & & & & 50.38 \\
\hline Total Scale Reliability Alpha & & & & & & 0.83 \\
\hline KMO & & & & & & 0.76 \\
\hline
\end{tabular}

TABLE IV: FACTOR ANALYSIS OF PULL MOTIVE ITEMS

\begin{tabular}{|c|c|c|c|c|c|c|}
\hline Pull Factors & Factor loading & Communality & Eigen Value & Variance & Me-an & S.D. \\
\hline Novelty & & & 2.09 & 20.95 & 3.00 & 0.86 \\
\hline $\begin{array}{l}\text { 1. Attending a green event has always been a dream } \\
\text { for me. }\end{array}$ & 0.87 & 0.80 & & & & \\
\hline $\begin{array}{l}\text { 3. To see some famous persons (actors or artists) } \\
\text { makes me want to visit a green event. }\end{array}$ & 0.79 & 0.71 & & & & \\
\hline $\begin{array}{l}\text { 7. The green event is the only reason I travelled } \\
\text { towards the destination. }\end{array}$ & 0.75 & 0.66 & & & & \\
\hline Self-development & & & 1.31 & 13.07 & 3.91 & 0.55 \\
\hline $\begin{array}{l}\text { 6. I would like to learn more knowledge about the } \\
\text { green event. }\end{array}$ & 0.82 & 0.75 & & & & \\
\hline $\begin{array}{l}\text { 2. Attending a green event makes me realize to be an } \\
\text { environmentalist. }\end{array}$ & 0.61 & 0.52 & & & & \\
\hline $\begin{array}{l}\text { 8. I would like to experience the culture of the } \\
\text { place/park where the green event is held. }\end{array}$ & 0.52 & 0.41 & & & & \\
\hline Natural resources & & & 1.21 & 12.10 & 4.16 & 0.62 \\
\hline $\begin{array}{l}\text { 5. I would like to learn something about the } \\
\text { destination where the green event is held. }\end{array}$ & 0.71 & 0.55 & & & & \\
\hline $\begin{array}{l}\text { 4. The beauty of the event location makes me want to } \\
\text { visit a green event. }\end{array}$ & 0.60 & 0.49 & & & & \\
\hline Easy access and affordable & & & 1.03 & 10.34 & 3.69 & 0.67 \\
\hline $\begin{array}{l}\text { 9. The inexpensive price level makes me want to visit } \\
\text { a green event. }\end{array}$ & 0.76 & 0.60 & & & & \\
\hline $\begin{array}{l}\text { 10. The easy transportation makes me want to visit a } \\
\text { green event. }\end{array}$ & 0.54 & 0.51 & & & & \\
\hline Total Variance explained & & & & & & 56.46 \\
\hline Total Scale Reliability Alpha & & & & & & 0.79 \\
\hline KMO & & & & & & 0.73 \\
\hline
\end{tabular}


To identify motivational dimensions, principal component factor analysis was used to group the push and pull motive items with characteristics. Six push motivational factors were analyzed using Varimax Rotation procedure to delineate the underlying dimensions associated with green event tourists' motivations. The same procedure was also applied to 10 pull motive items. All factors had an eigenvalue greater than one. The composite reliability test indicated that the reliability coefficients for push factors stood at $0.83,0.79$ for pull factors, and 0.77 for constraints Items.

Table III reports that the factor analysis of 17 push attributes results in six factors grouping, which accounting for 50.38 per cent of the variance. The factor groupings of push factors are 'socialization', 'prestige', 'entertainment', 'self-exploration', 'relaxation', and 'escapism'. 'Socialization' is the most important push motivational factor to attend a green event, and this explained 11.19 per cent of variance (eigenvalue is 1.90). The second most important factor is 'prestige' with a variance score of 9.76 . These two factors reflect the respondents desire to socialize with people and fulfill prestige by attending a green event.

Table IV reports that the factor analysis of 10 pull attributes results in four factors grouping. They are 'novelty', 'self-development', 'natural resources', and 'easy access and affordable'. These groupings accounted for 56.46 per cent of the variance. 'novelty' is the most important pull motivational factor to green event visitors, and this explained 20.95 per cent of the variance (eigenvalue is 2.09) the second most important pull factor is 'self-development' with a variance score of 13.07. these two factors demonstrate that green event visitors are pulled by some famous persons (actors or artists), green event itself, being knowledgeable, or environmentalism, etc.

\section{CONCLUSIONS}

This study offers an attempt to understand green event tourist motivation. The study suggests that the conceptual framework of push, pull, and constraint factors in the literature was generally supported. The study reconfirms that green event tourists' behavior is driven by internal and external factors. In other words, they decide to go on a green event because they want to fulfill their intrinsic desire, and at the same time, their decisions on where to go are based on destination attributes and constraints.

Looking into factors identified as push attributes, the study claimed that the needs for prestige, entertainment and relaxation are among most important motives which trigger the need to attend green events. The evidence is consistent with Mohammad and Som's research results that people travel with specific motives to fulfill prestige, attain entertained and feel relaxed (2010). The pull attributes, on the other hand, demonstrate that the factor of natural resources is regarded as the most important one to promote repeat visits. The country should capitalize on its heritage, natural attractions, and culture. Nevertheless, the pull factor of self-development is considered as second important attribute to attract green event tourists. Obviously, majority of green event tourists are willing to attend green events due to achieve some kind of self-realization.

\section{RESEARCH LIMITATIONS}

The findings of this study were based on one green event. The geographic setting of the region and the event's location limit the generalizability of the findings. The selected method of questionnaire-based has several disadvantages. The main shortcoming is the fact that it only considers visitors of green events and not persons who decided not to go. Furthermore the reliability and accuracy of the answers on the questions was sometimes doubtful. This study does not examine the interactions among the push and pull factors.

Moreover, the author had difficulties finding appropriate candidates. In the limited cases somebody was found, people tended to be very reserved and have difficulties expressing their attending motives sometimes. Time constrains were the main reason not to participate.

\section{REFERENCES}

[1] P. Bohdanowicz, "Environmental awareness and initiatives in the Swedish and Polish hotel industries-survey results," Hospitality Management, vol. 25, pp. 662-682, 2006.

[2] K. L. Andereck, "Tourists' perceptions of environmentally responsible innovations at tourism businesses," Journal of Sustainable Tourism, vol. 17, no. 4, pp. 489-499, 2009.

[3] A Greener Festival. [Online]. Available: www.agreenerfestival.com

[4] C. Ryan and I. Glendon, "Application of leisure motivation scale to tourism," Analysis of Tourism Research, vol. 25, no. 1, pp. 169-184, 1998.

[5] B. A. Mohammad and A. P. Som, "An analysis of push and pull travel motivations of foreign tourists to Jordan," International Journal of Business and Management, vol. 5, no. 12, pp. 41-49, 2010.

[6] S. S. Kim, C. Lee, and D. B. Klenosky, "The influence of push and pull factors at Korean national parks," Tourism Management, vol. 24, no. 2, pp. 169-180, 2003

[7] D. B. Klenosky, "The 'pull' of tourism destinations: A means-end investigation," Journal of Travel Research, vol. 40, no. 2, pp. 385-395, 2002.

[8] M. Kozak, "Comparative analysis of tourist motivations by nationality and destinationsm," Tourism Management, vol. 23, no. 3, pp. 221-232, 2002

[9] G. Prayag and C. Ryan, "The relationship between the push and pull factors of a tourist destination: The role of nationality-An analytical qualitative research approach," Current Issues in Tourism, vol. 14, no. 2, pp. 121-143, 2011.

[10] MOTC, The Status of Taiwan's Tourism \& Recreation Industry, Department of Investment Services, Ministry of Economic Affairs, Government Tourism Bureau, Republic of China (Taiwan), 2013.

[11] M. Argan, "Eglence pazarlamasi," Detay Yayincilik, Ankara, 2007.

[12] A. Eckerstein, "Evaluation of event marketing," International Management Master Thesis, vol. 25, Goteborg University, 2002.

[13] J. R. Silvers, Professional Event Coordination, John Wiley \& Sons Inc., New Jersey, 2004.

[14] G. Berridge," Events design and experience," Events Management Series, First Edition, Elsevier, 2007.

[15] J. Goldblatt, Special Events: Leadership for a New World, Hoboken, New Jersey John Wiley \& Sons, 2005.

[16] H. Kose, M. T. Argan, and M. Agran, "Special event management and event marketing: A case study of TKBL all star 2011 in Turkey," Journal of Management and Marketing Research, pp. 1-11, 2011.

[17] N. Theocharis, "Event tourism: Examining the management of sports events from a physical approach," Synenergy Forum, Athens, 2008.

[18] D. B. Park and Y. S. Yoon, "Segmentation by motivation in rural tourism: A Korean case study," Tourism Management, vol. 30, pp. 99-108, 2009.

[19] T. Robinson and S. Gammon, A Question of Primary And Secondary Motives, 2004

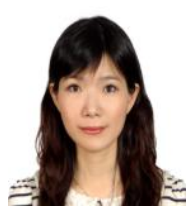

Yu-Fen Chen was born inTaipei, Taiwan, 1970. She got Doctoral Degree in University of Missouri, USA. She presents professional occupation is an associate professor in Chihlee Institute of Technology, Taiwan. Her research interests include Tourism related subjects, education technology application, and so on. 